\title{
Modeling Post-Operative Cognitive Dysfunction in Zebrafish
}

\author{
Bill J. McElroy'1, Julie L. Mustard1, Syed Kamran'1, Catherine P. Jung², \\ Katie L. Bakken', Norbert W. Seidler ${ }^{1,2}$ \\ ${ }^{1}$ Division of Basic Science, Kansas City University, Kansas City, MO, USA \\ ${ }^{2}$ Department of Anesthesiology, University of Missouri/Saint Luke's Hospital, Kansas City, MO, USA \\ Email: nseidler@kcumb.edu
}

Received 23 August 2016; accepted 13 September 2016; published 16 September 2016

Copyright (C) 2016 by authors and Scientific Research Publishing Inc.

This work is licensed under the Creative Commons Attribution International License (CC BY). http://creativecommons.org/licenses/by/4.0/

(c) (i) Open Access

\begin{abstract}
Permanent post-operative cognitive dysfunction (POCD) is a grim outcome to an estimated $6 \%$ of elderly surgical patients. Volatile anesthetics impact neuronal tissue independent of effects attributed to the physical trauma of the surgery itself. While it is recognized that all aspects related to surgery may contribute to cognitive loss in some manner, the present paper focuses on the role of volatile anesthetics in promoting POCD. There is an increased risk of onset and progression of Alzheimer's disease (AD) from POCD, implying that the neuropathogenesis between the two is similar. Human studies, being ethically limited in scope, require animal models as a substitute. While the literature using rodent models contains valuable information, we believe that the accessible and practical zebrafish will greatly enhance our further understanding of the molecular mechanism of POCD as it relates to AD. Disease genes and fundamental neurobehaviors of these teleost fish mirror those of mammals and humans, validating their use as a core research model for AD. Since the gradual senescence seen in zebrafish also resembles that found in humans, we numerically correlated the two lifespans, offering researchers a computational tool. Zebrafish, being aquatic animals, necessitates the use of miscible compounds, such as trifluoroethanol, whose anesthetic potency we are presenting. We also review the rodent and zebrafish literature relevant to POCD. Continued research with the leading-edge zebrafish unlocks the possibility that, in the future, perioperative intervention will prevent POCD.
\end{abstract}

\section{Keywords}

Zebrafish, Post-Operative Cognitive Dysfunction, Dementia, Aging, Anesthesia

\section{Introduction}

Post-operative cognitive dysfunction (POCD) is described as a decline in normal cognitive function that is pre-

How to cite this paper: McElroy, B.J., Mustard, J.L., Kamran, S., Jung, C.P., Bakken, K.L. and Seidler, N.W. (2016) Modeling Post-Operative Cognitive Dysfunction in Zebrafish. Advances in Alzheimer's Disease, 5, 126-141.

http://dx.doi.org/10.4236/aad.2016.53009 
sumably brought on by surgery. The impairment is seen as a loss in several cognitive parameters (i.e. memory, mental acuity, and understanding of language), as well as an observed withdrawal from and a decrease in social interaction. While these neuropsychological deficits were initially thought to occur days after an operation that resolve within a year, they may enhance further cognitive decline that results in dementia later in life.

In the 1970s, articles appeared that suggested a link between surgery and impaired cognitive function, most notably in patients undergoing cardiac surgery. These observational reports were followed up by prospective population studies in the 1980s that established the relationship between cardiac surgery and subsequent cognitive loss [1]. Despite the progressive changes in surgical procedures, more recent prospective studies continued to support this linkage [2] [3], further establishing the significance of POCD.

In addition to the susceptibility of POCD following cardiac surgeries, some patients that undergo non-cardiac procedures involving general anesthesia also present with POCD. The elderly are the most vulnerable patient population [4]. Another risk factor includes the patient's level of education, suggesting that a "cognitive reserve" in individuals with higher levels of education offer a protection against POCD. The concept of "cognitive reserve” indicates biological features, such as greater synaptic density and neuronal volume, both of which diminish in aging [5] and Alzheimer's disease (AD) [6]. These findings suggest a linkage between POCD and AD.

A question, therefore, arises: does POCD lead to AD? It has already been proposed that POCD increases the risk of onset and the progression of $\mathrm{AD}$ [7] [8], implying that the neuropathogenesis between POCD and AD is similar. These authors indicate that POCD contributes to a loss in "cognitive reserve", predisposing individuals to AD.

The specific causal factors of this loss in "cognitive reserve” still remain to be elucidated. Major operations, in which general anesthesia is used, trigger certain cellular processes that have a detrimental effect on the diverse cognitive functions of the brain. One must consider that the surgical event, juxtaposed to the anesthetic agents themselves, may exert its effects through different pathophysiological mechanisms. Interestingly, patient co-morbidities and the duration of anesthesia are independent risk factors for POCD [4], suggesting the importance of all aspects of surgery. Potential perioperative events, such as cerebral hypoxia (i.e. low $\mathrm{O}_{2}$ ) [9] [10] and hypocapnia (i.e. diminished $\mathrm{CO}_{2}$ ) [11], may directly lead to neuronal injury. Additionally, the neurohormonal and inflammatory responses [12] to the physical stress of surgery may initiate metabolic changes that are detrimental to the central nervous system. Volatile anesthetics appear to impact neuronal tissue in a manner independent of those effects attributed to the physical trauma of surgery. While it is recognized that all of the aspects that are related to surgery may contribute to cognitive loss in some way, the present paper focuses on the putative role of volatile anesthetics in promoting POCD.

The clinical criteria for a diagnosis of dementia associated with AD include a progressive decline in memory and cognitive functions, such as language, visuospatial and executive. These acquired deficits are far greater than expected for one's age, showing significant impairment in daily activities. The dementias associated with POCD are typically defined by performance on neuropsychological tests without indication of significant functional impairment of daily living. One third of those enrolled in the International Study of Post-Operative Cognitive Dysfunction (ISPOCD) were Danish; and Steinmetz and colleagues [13] examined the effects of POCD on functional impairment (namely, withdrawal from the labor market, the need for social-financial assistance and nursing home placement) in these Danish patients. The researchers concluded that the cognitive dysfunction that occurred after non-cardiac surgery was associated with withdrawal from the labor market and with dependency on social-financial assistance. Also, POCD at 3 months was associated with increased mortality. In a review of epidemiological evidence [14], Setz and colleagues concluded in 2013 that there is little literature support in human studies that $\mathrm{AD}$ develops as a consequence of exposure to general anesthesia. There are likely considerable differences in susceptibility among individuals, contributing to the disparate observations in the human studies literature. The authors [14], however, acknowledge that there is a dearth of quality research and that continued surveillance in this area is warranted, particularly as animal models have clearly demonstrated AD pathology following exposure to volatile general anesthetics [15]-[17].

Our current understanding of the relationship of exposure to volatile anesthetics and cognitive decline is incomplete, suggesting a need for further research. The ability to obtain information and knowledge from human clinical observations and studies is constrained given the necessary ethical concerns and our current technological limitations. Hence, research using an animal model enhances our progress towards a greater understanding of the molecular mechanisms in POCD and how they relate to AD. The current research approach using rodents offers opportunities for testing diverse working hypotheses, and has been used successfully in obtaining valuable 
data. We think that an alternate animal model, such as zebrafish, may enhance the ability of researchers to interrogate various research questions. Zebrafish are an excellent alternative to mice in brain studies, as housing and care are easier and much less expensive; they also have superior fecundity, producing hundreds of offspring per pair per mating vs five to ten in mice. In a comprehensive genomic comparison of shared genes with humans [81], zebrafish showed $70.1 \%$ versus $82.7 \%$ for mouse; and, $84 \%$ of human disease genes are matched in zebrafish. Zebrafish telencephalon also represents a forebrain that is on the evolutionary continuum on the same ancestral node as mammals. Zebrafish may enable researchers to examine diverse behavioral endpoints that may accelerate the discovery of fundamental processes in POCD and AD, bridging biology to behavior in elucidating molecular mechanisms that may be amenable to rational interventional strategies.

\section{Human Studies}

Anecdotal reports as far back as 1955 [18] suggested that cognitive decline may persist after surgery, particularly in the elderly. The observed decline in cognitive function within the postoperative period, particularly in cardiac patients, eventually brought attention to the possible presence of POCD and further elucidated the necessity to define how the POCD patient would present and at what prevalence. In 1982, Savageau and colleagues [1] administered a number of cognitive exams to patients before and shortly after their cardiac operations and out of 227 patients, he observed that $11 \%$ to $17 \%$ had a loss of cognitive function greater than one standard deviation on all specific test scores. In addition, 30\% showed a decline on at least one cognitive test that was administered within days following surgery.

The possibility that POCD was not merely a transient event, but rather a phenomenon that continued several years following surgery, was worth further investigation. Some studies suggested a substantial association between cognitive loss immediately following cardiac operations, such as coronary artery bypass surgery (CABG), and that significant cognitive dysfunction persisted later in life. In a longitudinal assessment [3] following 261 patients who underwent CABG, the incidence of cognitive decline was 53\% at discharge, 36\% at six weeks post-surgery, $24 \%$ at six months, and $42 \%$ at five years. More significantly, the study showed that those patients presenting with the most drastic drop in cognitive function from baseline at discharge were more likely to present five years later with cognitive impairments. Their study was published in 2001. The researchers performed cognitive tests, both pre- and post-operatively, concentrating on four areas of neurocognitive function. Baseline (i.e. pre-operative) scores with standard deviations were obtained for each of these four areas. The four cognitive domains were: 1) verbal memory and language comprehension (i.e. short-term and delayed); 2) abstraction and visuospatial orientation; 3) attention, psychomotor processing speed; and 4) visual memory. The neuro-psychological tests included the Randt Memory Test, the Digit Span and Digit Symbol Subtests of the Wechsler Adult Intelligence Scale-Revised, the Benton Revised Visual Retention Test, and the Trail Making Test. While the authors generated a composite cognitive index that was representative of all of the individual domain scores, the criterion for neurocognitive decline was designated as a one standard deviation drop in a patient's test scores in any one of the four areas. The assessment criterion was based on a consensus statement published in 1995 [19]. The authors [3] indicated that the incidence of cognitive decline initially decreased from discharge to six months then rose again at five years, suggesting a long term deterioration of symptoms. The long-term cognitive decline was dependent on several factors: older age, fewer years of education and evidence of cognitive decline at discharge. More years of education offers a level of protection, which was previously identified for AD [20]. It is important to note that only 172 patients of the initial 261 [3] were assessed at the five-year time point, suggesting that attrition of study patients may greatly underestimate the significance of cognitive decline.

In addition to long-term dysfunction, the question arose of whether cardiopulmonary bypass was a major risk factor for POCD, or if POCD could be identified within other patient populations. In a multicenter study [4], investigating outcomes following major abdominal and orthopedic surgery, it was observed that $9 \%$ of 1218 patients presented with POCD three months after surgery. The study showed that increased age, duration of anesthesia, minimal education, and postoperative infections and complications were all associated with early POCD, while increased age was a major risk factor beyond the immediate postoperative period.

The ISPOCD involved two phases, the first of which (i.e. ISPOCD-1) began in 1994 and ended in 1998. The second follow-up phase (i.e. ISPOCD-2) started in 1998 and ended in 2001 . While the first study tested whether age, hypoxemia and low blood pressure contribute to POCD, the only confirmed incidence increases with age. Early POCD (i.e. seven days after surgery) affected $26 \%$ of the patient population and long-term (i.e. three 
months after surgery) occurred in $10 \%$ of the patients in this study.

\subsection{Symptomology}

Independent of surgery and exposure to anesthetics, a decline in neurocognitive function with age appears linked to genetic (e.g., ApoE variant 4) and environmental factors (e.g., cardiovascular risk factors) [21]. Several studies indicate that this age-related decline in cognitive performance is gradual [22] [23]. Animal models that look at POCD would have to demonstrate a similar gradual decline in cognitive performance as a backdrop to the effects of anesthesia. This concept is discussed further below.

The assessment of cognitive function in patients can be evaluated through a series of neurocognitive exams administered prior to surgery, thereby establishing a baseline, then at varying time intervals postoperatively. The exams [1] [3] [4] typically involve memory and recall, verbal understanding, visual retention and reproduction, psychomotor processing speed, and cognitive sequencing. Analysis of the data indicates a patients level of functioning [2] [3], establishing an overall, and perhaps comprehensive, neurocognitive status. A decline in this baseline mental status is found in patients suffering from POCD. Evidence [2] [3] suggests a possible multistage course in POCD and its association with dementia.

Selnes and colleagues [2] reported cognitive changes occurring five years after coronary-artery bypass surgery. They started with 172 patients and were able to assess 102 patients at the five-year time point. Eight cognitive domains were assessed: 1) verbal memory, via the Rey Auditory Verbal Learning Test; 2) visual memory, via the Rey Complex Figure (i.e. the delayed recall test) and Digit Symbol Tests; 3) language, via the Boston Naming Test; 4) visuoconstruction, via the Rey Complex Figure (i.e. copy) Test; 5) attention, via the Digit Span Subtest; 6) psychomotor speed, via Digit Symbol Subtest and written alphabet; 7) executive function, via the Stroop Test; and 8) motor speed, via Grooved Pegboard Test. In six out of eight tests, patients showed a decline at the five-year time point, relative to the one-year performance level. Relative to pre-operative baseline values, in two of these tests (namely, \#4 and \#6), patients showed a decline at five years. Interestingly, early AD neuro-psychological features include similar cognitive domains [24].

ISPOCD-1 and ISPOCD-2 were driven in part by anecdotal information from the relatives of elderly patients. Anecdotal reports, among family practice physicians, suggested that POCD was common in elderly patients. It was not unusual to hear a story of an elderly relative, typically male, being admitted to the hospital for major surgery and then several months later, while the operation appeared successful, the individual seems to, now, exhibit some signs of social impairment and appears to be mentally sluggish. To assess mental status, the psychometric tests included the Verbal Learning Test (memory), the Concept Shifting Test (assessing, visual conceptual and visuomotor tracking), the Stroop Color Word Interference Test (assessing, attention), Paper and Pencil Memory Scanning Test (assessing, sensorimotor speed), the Letter-Digit Coding Test (assessing, visual memory, visuoconstruction and motor functions), and the Four Boxes Test (assessing, psychomotor speed). The 3-month incidence of POCD of patients middle-aged (40 - $60 \mathrm{yr}$ ) and older (>60 yrs), after minor surgery, was $6.2 \%$ and $6.6 \%$, respectively, with an association to depression [79] [80].

While the etiology of POCD is yet to be completely elucidated, researchers have implicated surgical factors (i.e. invasiveness and duration of surgery) as well as the effects of anesthetics. There is thought to be associations of POCD with pre-existing clinical manifestations, such as diabetes, obesity and atherosclerosis, although the molecular correlates have not been fully understood. Unequivocally, increased age and low education are contributing factors. Human studies are complicated due to the extremely diverse confounding factors of lifestyle and genetics, which are eliminated using controlled animal models.

\subsection{Molecular Mechanisms}

Perioperative factors (i.e. hypoxia, hypocapnia) have been put forward as possible triggers for the neuro-pathogenesis of POCD, as well as that of AD. The risk of AD dementia is significantly elevated in patients, who have experienced prolonged episodes of hypoxia [9] [10], during which amyloid precursor protein (APP) and amyloid beta peptide (ABP) levels rise [25] [26], concurrent with a decrease in APP processing via alpha-secretase [27]. Hypocapnia causes elevation in ABP, increased cellular apoptosis and initiates neurodegeneration via caspase-3 activation [11], suggesting that it also may promote $\mathrm{AD}$ neuropathogenesis.

The neuroinflammatory response during surgery may also play a role, and some have suggested that inflammation is a major factor in the occurrence of both POCD and AD [28]. Chemical mediators of the peripheral in- 
flammatory response to surgery may cross over into the central nervous system (CNS). Moreover, direct CNS inflammation, via microglial activation, may involve local release of inflammatory mediators that affect neurotransmission at the synapse [29] [30].

Alternately, anesthetics may directly impair neuronal function. Animal models have shown that anesthetics can lead to the formation of ABP plaques, elevated tau hyperphosphorylation, and memory impairment [7] [31]-[33]. Exposure to isoflurane, for example, leads to long-term deficits in cognitive function as evidenced in treated aged rats performing tasks requiring spatial memory [34]. Anesthesia-only studies with humans are constrained by ethical challenges, demonstrating a need for further animal model research.

\section{Rodent Model}

The neuro-pathogenesis of POCD due to surgical stress has been investigated using rodents. An upregulation of angiotensin II and its corresponding receptor in the hippocampus was observed in surgery-induced cognitive impairment using rats [35]. This suggests that activation of the brain renin-angiotensin system may play a role in the development of POCD in aged rats. Pre-treatment with a receptor antagonist showed decrease in: cognitive loss evaluated by the Morris water maze task; blood-brain barrier (BBB) permeability; and glial reactivity. This further supports the link between brain renin-angiotensin system and POCD in surgical stress. In a study with mice [36], abdominal surgery was performed using local, rather than general, anesthesia on 18mo wild-type (WT), 9mo AD transgenic mice, and 9mo WT mice. Post-operative increases in brain ABP were seen in the 18mo WT and 9mo transgenic model but not the 9mo WT. The use of a gamma-secretase inhibitor decreased the accumulation of ABP and cognitive impairment seen in the 18mo WT. This suggests that cognitive impairment can be induced independent from general anesthesia and that some combination of surgery-stress, aging, and gene mutation is capable of inducing POCD [36].

Rodent studies also implicate volatile general anesthetics in cognitive impairment. Using Evans Blue dye quantification to analyze hippocampal BBB permeability, the study [37] demonstrated that surgery impaired cognitive function and increased dye leakage into the hippocampus of aged rats. The researchers also observed altered expression of cell junction proteins following surgery that was consistent with loss in BBB function. Furthermore, the study demonstrated that 2 hr of 1.5 MAC (mean alveolar concentration) of sevoflurane increased cognitive impairment and BBB permeability.

Pro-inflammatory cytokines stimulate hyperphosphorylation of tau protein with subsequent synaptic and cognitive dysfunction, as described in the review paper by Luo and colleagues [38]. They state that isoflurane transiently increases neuro-inflammatory cytokines, which link to POCD and posit that the main risk factors for POCD are advanced age and duration of anesthesia.

Post-operative pain, and associated stress of surgery, may contribute to POCD. Aged rats, undergoing laparotomy, that were exposed to isoflurane showed cognitive loss, while those exposed to isoflurane plus analgesia (i.e. local ropivacaine or systemic morphine) showed no loss [39]. Isoflurane alone (1.2\% for $2 \mathrm{hr}$ ), with no surgery, did not affect cognition. Up-regulation of NMDA (N-methyl-D-aspartate) receptors correlated with postoperative pain and the development of memory deficits, suggesting that management of pain may be a critical step in the prevention of POCD in the elderly. Young (3mo) and aged (18 - $20 \mathrm{mo})$ rats, which were examined prior to and after abdominal surgery [40], showed that age correlated with changes in behavior and microglial activation within the CA1 hippocampal region. The authors suggest that older individuals exhibit increased neuroinflammation following surgery that can impact behavior and spatial learning.

Adult rats, which were treated with lipopolysaccharide (LPS) following surgery [41], showed IL-1 upregulation and cortical and hippocampal degeneration, suggesting that stress associated with surgery plays a pivotal role in POCD. Acetylcholinesterase inhibitors improved cholinergic transmission and decreased neuroinflammation, suggesting that the cholinergic anti-inflammatory pathway is a neurohumoral mechanism for the prevention of post-operative neuroinflammation and degeneration.

In a study that only looked at exposure to anesthetics in the absence of the stress of surgery [42], aged rats (20 mo), which were exposed to isoflurane (1.3\% for $4 \mathrm{hr})$, demonstrated cognitive deficits. The researchers investigated pretreatment with minocycline, an antibiotic with anti-inflammatory properties. Pretreated subjects showed reduced cognitive deficits. Suppression of IL-1 and caspase-3 were observed within the CA1 region of the hippocampus, as well as evidence of protection of the synaptic ultrastructure. Minocycline appears to have neuroprotective effects, independent of its antibiotic properties. This study unequivocally showed that isoflurane alone impaired the synaptic ultrastructure in the hippocampal CA1 region, increasing synaptic width and decreasing 
the area of post-synaptic density. These observations are consistent with a study that demonstrated that isoflurane increases the levels of TNF-alpha, IL-6 and IL-1beta in brain tissues and in primary neurons of mice [43].

Wang and colleagues [44] investigated the effects of isoflurane on the cholinergic system within aged rats and its correlation to learning and memory impairment. The researchers observed that aged rats treated with anesthetics showed differential susceptibilities, exhibiting severe and mild impairment groups. The grouping was designated via the Morris water maze test. The severe impairment group exhibited decreased acetylcholine in brain as measured immediately following the water maze test, suggesting that isoflurane may impair learning and memory via the cholinergic system.

\section{Zebrafish Model}

Despite all of the current advancements in our understanding of the unintended consequences of general anesthetics, the molecular mechanisms associated with POCD remain to be fully elucidated. Alternate animal models may prove useful. Others have promulgated the importance of using zebrafish as a model for studying neurological diseases [45], including AD [46]. We extend this perspective and think that zebrafish would be a useful animal model for POCD. Cognitive deficits are recognized as a common feature of many diverse neurological disorders, including AD [47]. Furthermore, there is a general decline in cognitive performance with age-a growing global concern as the relative percent of older individuals increases in many countries, such as the United States. Given the current and future impact of cognitive impairment on our society, if only for those cases due to aging, there is a need for an effective translatable animal model to study mechanisms of cognition. That surgery in some patient populations adds to the risk of cognitive loss also supports the call for developing a predictive model for POCD. We think zebrafish can serve that purpose.

\subsection{Comparing Zebrafish and Human Lifespans}

Zebrafish holds the potential to be an efficient model for studying neurobehavioral and biological aspects associated with aging. Curiously, zebrafish exhibit gradual senescence, a feature of human aging. Kishi and colleagues [48]-[54] have, since 2003, extolled the concept of using zebrafish as a model for aging, publishing in this area for over a decade and demonstrating the phenomenon of gradual senescence, similar to that found humans. Histological examination of the liver showed an accumulation of age-related pigments (i.e. lipofucin and "drusen"-like) in older zebrafish [52], again similar to that found in humans.

To use zebrafish as an effective model organism, individuals in a study need to be precisely identified as being at a particular stage in the life cycle. The standard divisions of zebrafish development are well-defined [55] prior to adulthood (Figure 1), and so, research subjects are accurately staged during early development with comparative correlates to humans. However, once the zebrafish reach adulthood, that is $90 \mathrm{dpf}$ (days post-fertilization) in standard $\mathrm{AB}$ wildtype strain, there are no subsequent charted life stage designations. It is important to note that staging the life cycle points can vary in genetically-modified strains of zebrafish. In the present discussion, we are using the standard $\mathrm{AB}$ wildtype strain as the representative model for this species.

There are many advantages to standardized developmental assignment of experimental subjects, which includes comparing results from different laboratories, performing analyses of individual variations, and making

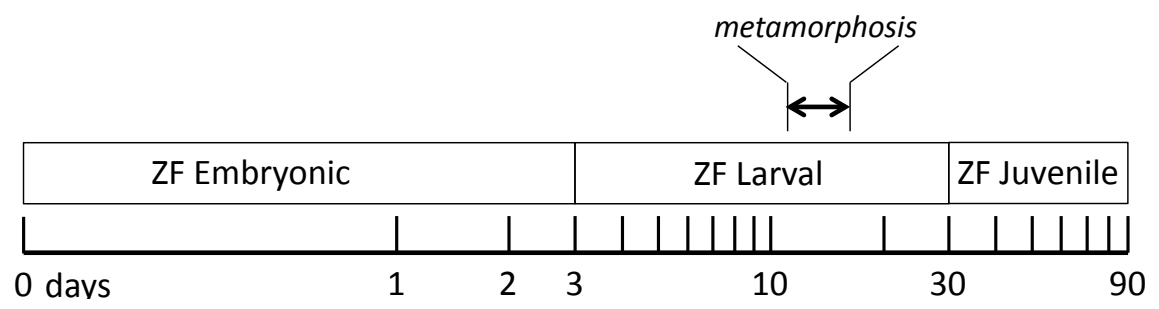

Figure 1. Timeline of zebrafish early development. The stages are indicated as horizontal blocks with the time frame shown below in logarithmic scale. A sub-stage, commonly referred to as "metamorphosis", in which tissues undergo rapid transformation, occurs during the so-called larval stage. There is general agreement that zebrafish (ZF) adulthood begins at $90 \mathrm{dpf}$. The focus of the present paper is the zebrafish adult stage; therefore, the well-documented correlation to human early development is not addressed here. 
comparisons across species [56]. In the life cycle period defined as adulthood, the need for more-precise staging continues to be a priority to avoid skewing inter-experimental results when grouping different age cohorts together. As with humans, zebrafish exhibit subtle physical, behavioral and metabolic changes throughout adulthood. Accurate full-life staging is desirable in order to obtain reproducible results that are ultimately translatable to humans. Attempts to bridge these two species' adult life stages may offer better insight into human biological questions, such as the chronic diseases of aging (i.e. dementias), and pertinent to this paper, POCD.

The various stages of early zebrafish development (shown in Figure 1) reflect a logarithmic trajectory. Like most teleost fishes, zebrafish fertilize and reproduce externally, hatching in $3 \mathrm{dpf}$, still physically incomplete, not unlike an extra-uterine fetal marsupial. The embryonic stage occurs in a transparent chorion, whereby the growing organism is dependent on its yolk sac, which is depleted by 8 dpf. Organ development is basically finished by 36 hpf (hours pf), although a metamorphosis period, at about 12 - 15 dpf, must occur in order to reach physiological maturation and anatomical reconfiguration of the body systems. Gender determination also occurs during metamorphosis and is partially dependent on environmental temperature.

\subsubsection{Average and Maximum Lifespan Benchmarks}

The adult stage in zebrafish begins at the end of the juvenile stage (Figure 1), at 3 mpf (months pf), and proceeds to end of life, which is thought to be on average about 3 yrs [57]. The average lifespan (i.e. published as $42 \mathrm{mo}$ ) was determined using outbred zebrafish in captivity. Zebrafish in the wild are thought to live for only about one year. Gerhard and his colleagues [57] also reported that the oldest living individual in the study lived for a little over 5yrs. No other published works on experimentally determined zebrafish lifespan were found in the primary scientific literature. This single study [57] involved outbred zebrafish that may have exhibited a genetic advantage for longevity; and, as such, the results become an estimate for lifespan of inbred strains currently used in laboratories (i.e. AB wildtype). These researchers [57] also included an uncommon inbred zebrafish strain (i.e. golden sparse) that exhibited a lifespan (i.e. 36 mo on average) that was slightly less than the outbred strain.

We consider the average zebrafish lifespan of 36mo an outlier average, particularly when one considers that most laboratories cull their adult zebrafish by $24 \mathrm{mo}$ as they begin to display physical/skeletal distortion and increased susceptibilities to infection. In preparation of this review article, we used the zebrafish average lifespan benchmark of 36mo and linked it to the corresponding value for humans. In examining the literature for average human lifespan, we looked at data for life expectancy and thought that it would be appropriate to include a homogeneous culture that exhibited the highest life expectancy. In Japan, the 2015 data shows that females have a life expectancy of 86.8 years (accessed from http://www.who.int/mediacentre/news/releases/2016), representing the outlier average that we are linking to Gerhard study's [57] observation of 36 mo for the golden sparse strain of zebrafish. We used the human female outlier average since the other two benchmarks, discussed below, pertain to reproductive years, definable as female fecundity. We used another data point from the 2002 Gerhard study [57] to identify common benchmarks to correlate human and zebrafish lifespans, namely outlier end-oflife for the golden sparse breed (i.e. $58 \mathrm{mo}$ ), then linked the zebrafish maximum lifespan of 58mo to the corresponding value for humans.

The maximum lifespan of humans is predicted to be about 126 years [58], as assessed by demographic analysis of Swedish females. Curiously, if one averages the top ten maximum lifespan claims tabulated by the Gerontology Research Group, the mean value of 128 is calculated, which also happens to be the age of an individual in that list with the following note: “oldest believable claim” (accessed http://www.grg.org/Adams/J.HTM; the website states that the evaluation committee uses three independent pieces of demographic documentation, including one that dates back to the time of the claimant's birth). Most of the internet search documentation easily accessible contains the information of a French woman that lived for 122.5 yrs. In this analysis, we decided to choose the benchmark of 128 years of age as the human maximum lifespan to link to that of zebrafish, namely 58 mpf (months pf).

\subsubsection{Reproductive Years as Benchmarks}

We used two more benchmarks for correlating zebrafish and human adulthood, namely the average outliers for the starting point and ending point of their reproductive years, respectively. For zebrafish, there is general agreement that reproductive capability begins at 3mpf and ends at $1.5 \mathrm{ypf}$ (years pf), as outlier averages. For humans, the corresponding time points are 10 years and 53 years, respectively. The procedure we used to arrive 
at a single value for the oldest average human pregnancy is as follows. Due to an over-abundance of information on the internet, documenting separate individuals and their births, with little consolidation of the diverse data, we accessed the annotated, and well-cited, wiki page (https://en.wikipedia.org/wiki/Pregnancy_over_age_50, which was accessed on 06/09/2016). From the list provided, we omitted those with the following criteria: any pregnancy due to medical intervention (i.e. in vitro fertilization, fertility drugs, etc.), celebrity-related births (due to the doubt of their authenticity), births prior to 1900, and births from countries whose authenticity could be questioned (i.e. Cold-War era Soviet Union, Third World nations etc.). Following this exclusion process, we averaged the remaining natural and authenticated cases of live births. The result was 53 years of maternal age. For the youngest average human pregnancy, we performed the same process using the comprehensive list that was provided on another annotated, well-cited wiki page

(https://en.wikipedia.org/wiki/List_of_youngest_birth_mothers, which was accessed on 06/09/2016), yielding the result of 10 years maternal age.

\subsubsection{Zebrafish in Human Age Equivalent}

The narrow scientific requirements for adequate matching of inter-species adult benchmarks restrict us to the four. These benchmarks, above described (i.e. average and maximum lifespans and the earliest and latest reproductive timepoints), were correlated to one another. That is to say, we plotted the human benchmarks as a function of the respective zebrafish benchmarks (Figure 2). The best-fit curve generated a two-parameter power equation, $y=\mathrm{a}\left(x^{\mathrm{b}}\right)$, that gave a $p$-value of 0.0007 , where "a" equals 0.425 and "b" is 0.757 . It is important to note that this represents a testable estimator of age equivalent to allow researchers to generate hypotheses that can be experimentally tested.

For example, let us consider brain development in humans which is thought to reach maturity at 25 years [59], at least in terms of intellectual ability and psychosocial maturity. Using our derived equation shown in Figure 2, a testable hypothesis could be that brain development in the zebrafish, as assessed by neurobehavioral tests, should be expected to reach maturity at the zebrafish age equivalent of 226dpf, or $7 \mathrm{mo} 13 \mathrm{dpf}$

(https://www.symbolab.com/solver/equation-calculator). Human adult cognitive performance appears related to cortical activity that demonstrates a greater recruitment of cortical regions than that which occurs prior to adulthood [60]. Does such an inflection point, in zebrafish, occur during adulthood, and does it occur at about 226dpf? There may be other utilitarian possibilities for this H-eq equation that our laboratory is currently examining.

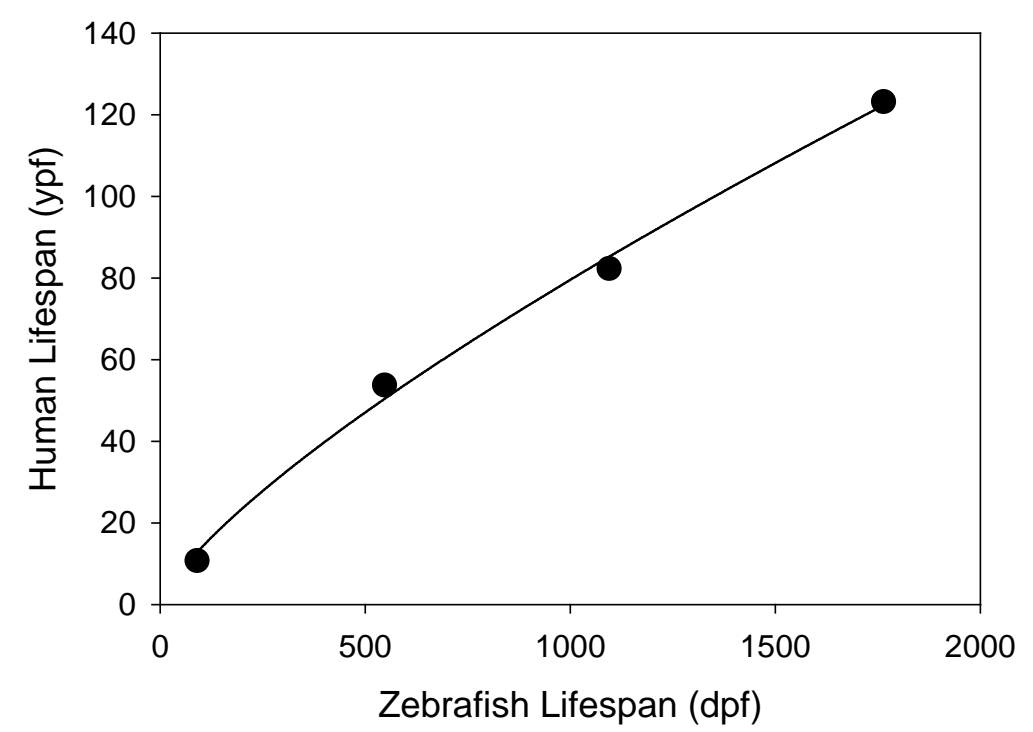

Figure 2. Correlation of human and zebrafish lifespans. Four benchmarks were used to correlate the human adult stage with that of the zebrafish. Human and zebrafish linear scales were in years and days, counting from fertilization (i.e. ypf and dpf, respectively). Human gestational period (0.75068 yr) was numerically added to each of the four human time points. The graph was plotted using SigmaPlot 12.5 (www.systatsoftware.com) with the "Curve Fit" command generating the best fit non-linear regression after 12 iterations. To estimate the human age equivalent $(\mathrm{H}-e q)$ of a given zebrafish, the formula is $\mathrm{H}-e q=\left(0.425 x^{0.757}\right)-0.751$, where $\mathrm{x}$ is the age, in dpf, of the zebrafish in question. 


\subsection{Effects of Anesthetic Agents}

Zebrafish is already being used to study memory-inhibiting drugs, as well as agents thought to enhance cognitive performance [61]. The impact of the socially-relevant stimulant, nicotine, on cognitive function, for example, can be effectively studied using zebrafish [62] with the ability of bridging biology with behavior, in this case understanding brain receptor activity [63]. Another relevant stimulant of human interest (i.e. caffeine) can be investigated using the zebrafish model, particularly with regards to understanding its effect on learning and memory [64]. There are diverse agents, which are known to act on the CNS, that affect memory function in zebrafish, including ketamine [65], scopolamine [66], NMDA-antagonist dizocilpine [67] and ethanol [68]. Ketamine, an NMDA-receptor antagonist, is used in surgery to induce sedation and analgesia. Kaleuff and his colleagues [65] observed that zebrafish exposure $(0.1 \mathrm{mM}$ for $20 \mathrm{~min})$ of sub-anesthetic levels of ketamine diminished anxiety, impaired memory (i.e. intra-session habituation) and disrupted social behavior (i.e. shoaling). Scopolamine, which is an acetylcholine muscarinic receptor antagonist that is given as a pre-medicine in surgery to minimize respiratory tract secretions and post-surgically for nausea, has an amnesic effect when given to zebrafish $(0.2 \mathrm{mM}$ for $1 \mathrm{hr})$ [66]. The acetylcholinesterase inhibitor, physostigmine, when given at $0.2 \mathrm{mM}$, resulted in rapid abrupt movement of treated zebrafish, described as seizure-like locomotor activity [69], which the researchers assigned to the increased production of nitric oxide. We think that these episodic bursts of swimming by zebrafish are common occurrences in control fish and easily measurable (Figure 3).

The absolute number and the periodicity appears to vary among individuals, and it remains to be determined whether the features of this normal episodic burst-swimming is age-cohort related. The phenomenon can be measured using neurobehavior programs, such as the Noldus Ethovision

(http://www.noldus.com/animal-behavior-research), by setting threshold acceleration to $20 \mathrm{~cm} / \mathrm{s}^{2}$ occurring over a $100 \mathrm{~ms}$ period.

\subsubsection{Anesthetic Preconditioning}

The biomedical definition of preconditioning is rather narrow and precise. Simply stated, preconditioning occurs when a transient sub-lethal insult protects against future fatal injuries. This phenomenon is observed in diverse organisms and typically refers to a specific tissue, such as brain, although other tissues have exhibited the capacity for preconditioning. The most common example is that a small heart attack protects cardiac tissue against a future massive heart attack. Regarding brain, as the majority of neurons do not regenerate, one can immediately recognize the clinical significance of protecting the brain against acute, and potentially lethal injuries, including trauma, surgical injury, ischemic stroke and neonatal hypoxia. Preconditioning also protects against the toxic agents used as models of neurodegeneration, suggesting that this phenomenon, once understood, can potentially stave off age-related diseases, such as $\mathrm{AD}$.

In order to consider applying this phenomenon to clinical intervention, even as a preventative measure, one must understand how preconditioning works. Certain stimuli trigger endogenous neuro-protective processes and their molecular underpinnings must be elucidated in order to identify key targets.

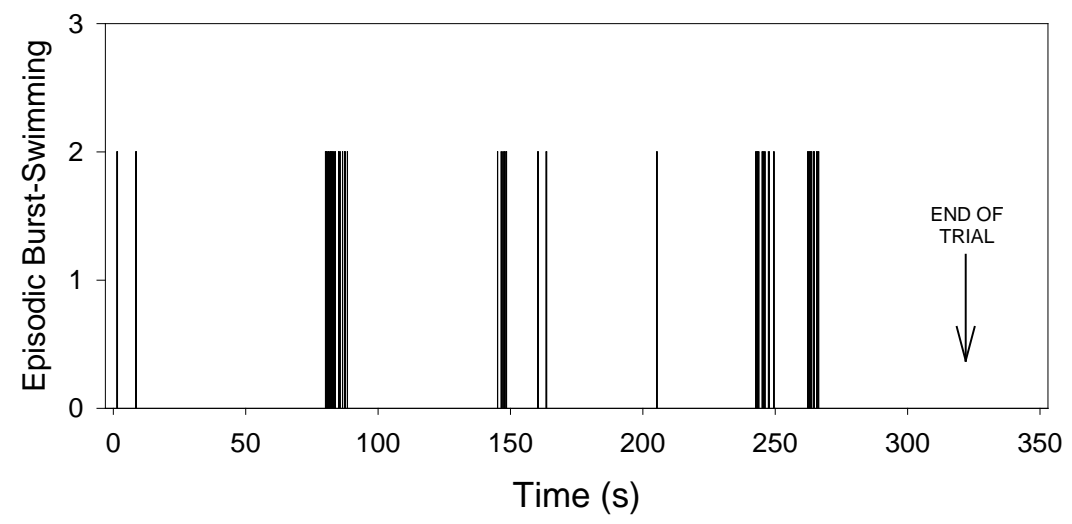

Figure 3. Features of adult zebrafish burst-swimming. An untreated adult-zebrafish in an open-field test (tank: $30 \mathrm{~cm} \times 30$ $\mathrm{cm}$ ) was video-recorded and each acceleration $\left(>20 \mathrm{~cm} / \mathrm{s}^{2}\right)$ was scored over time (vertical line, $\left.y=2\right)$. There was a periodicity of this behavior and the burst-swimming appeared as a high number of distinct accelerations grouped together over brief intervals of time. This behavior reflects neuromuscular integrity and would be amenable to study during zebrafish adulthood. 
The curious nature of this phenomenon is the wide diversity of preconditioning stimuli. In addition to environmental extremes (i.e. partial pressure of oxygen, temperature, etc.), brain tissue can be preconditioned with chemicals (i.e. toxins, pharmacological agents and anesthetics). Dirnagl and colleagues [70] postulate that nearly any stimulus — known to be harmful—can trigger neuroprotection when applied just below the threshold level of damage. The authors categorized three types of molecules involved in this process: sensors, transducers and effectors.

We propose that preconditioning is a process directly related to the mechanisms of POCD. We hypothesize that while young vibrant brain tissue can respond in a neuro-protective manner to a preconditioning agent, the older, less-resilient brains would be adversely affected, suggesting a need for studying the sensors, transducers and effectors in anesthetic preconditioning as a way of understanding the mechanisms in POCD.

In addition to the pharmacological effect on acetylcholine muscarinic receptors described above, physostigmine appears to elicit a preconditioning effect in zebrafish, as evidenced by telencephalon cell proliferation and increased iNOS expression [69]. Likewise, anesthetics likely have off-target effects that elicit preconditioning

Trifluoroethanol, an anesthetic mimetic, has a preconditioning effect on zebrafish, as observed in larvae [71]. Zebrafish larval behavior is well-characterized, representing valid endpoints of analysis. Larval behavior (i.e. freezing, shoaling and thigmotaxis) is amenable to quantitation for neuro-behavioral investigation. Thigmostasis occurs when the fish positions its body head-first and perpendicular to the perimeter wall of the container (i.e. culture dish, beaker, or tank), and thigmotaxis is "wall-hugging" behavior, swimming at the periphery. Neurobiologists consider this behavior as anxiety-related. Additionally, assessment of how larvae engage with their environment, particularly elementary feeding and shoaling behavior, also represent an area of investigation. Trifluoroethanol-exposed zebrafish larvae (i.e. doses at sub-anesthetic levels) exhibit a pattern of accelerated maturation of neuronal function, a neuro-phenotype that is attributed to preconditioning [71].

While the anesthetic potency of trichloroethanol, the active metabolite of chloral hydrate (i.e. one of the early general anesthetics), has been studied [72], the sedation effects of trifluoroethanol have not been published. We analyzed videos of adult zebrafish (400 dpf/13mpf; or, $38.9 \mathrm{H}$-eq years) immersed in various concentrations of trifluroethanol to determine the concentration at which complete immobility is observed (Figure 4).

The volatile nature of inhalational compounds is inherently incompatible with the aquatic environment of zebrafish. Trifluoroethanol holds an advantage over the inhalational anesthetics (i.e. isoflurane and sevoflurane), in

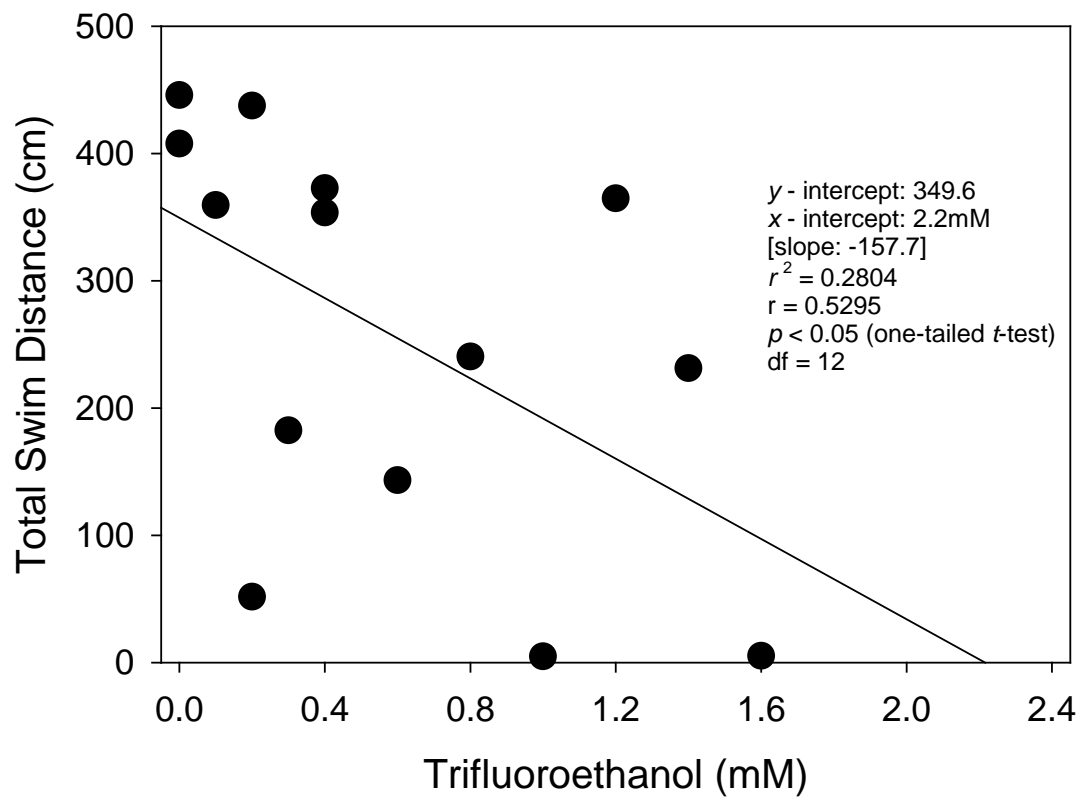

Figure 4. Anesthetic potency of trifluoroethanol. Zebrafish were kept at various concentrations of trifluoroethanol (5 min at $28^{\circ} \mathrm{C}$ ) prior to acquiring video clips $(1 \mathrm{~min})$, during which the total distance swam was measured, and then plotted as a function of concentration of trifluoroethanol. A linear regression line $(p<0.05)$ was generated using SigmaPlot 12.5 that calculated the $x$-intercept of $2.2 \mathrm{mM}$, consistent with the literature on the anesthetic potency of trichloroethanol [72]. The data spread may be due to variation among individual behavior. . 
that it is water soluble and therefore the concentrations of agent can be effectively dosed for aquatic animals. Using trifluoroethanol, a preconditioning effect on zebrafish larvae was elicited at low concentrations (100 $\mu \mathrm{M}$ for 3 hrs [71]). This sub-anesthetic dose eliminated the need to work at millimolar concentrations, which minimized collateral molecular targets.

\subsubsection{Zebrafish Learning and Memory}

We looked at the cognitive capability of adult zebrafish. Using a straight-forward habituation food reward design, we examined the ability of zebrafish to learn to associate a food reward with a specific color. This type of color discrimination paradigm for associative learning was previously used [73]. In a three chamber tank (containing doors connecting the center chamber with the two outer chambers), a single zebrafish was placed in the center chamber and was observed over a $5 \mathrm{~min}$ period for entrance into one of the two outer chambers. At the far end of each outer chamber was a color prompt: one, green; the other, red. Six un-treated control adult zebrafish were tested over an 18-day period. There were two trials each day. If the fish chose the green chamber, a single particle of dried food was given as reward. As soon as the fish swam into one of the outer chambers, the doors connecting the chambers were closed. Each trial was scored as follows: correct, incorrect or no choice. The results for each day were tabulated as the number of correct choices divided by the total number of trials, representing a fractional assessment of performance. This value was tracked over time (Figure 5).

This and other learning tasks can be used to correlate cognitive targets with biological endpoints. Our lab is interested in understanding the role of GABAergic receptors in learning and memory. Learning mechanisms in zebrafish have already been shown to be associated with acetylcholine and adenosine [74] and glutamatergic [67] signaling.

It is important to clearly delineate the role of cognitive-disruptors, or -enhancers (i.e. preconditioning agents), as having development-specific effects. Exposure during the various stages of development (i.e. embryonic, larval, juvenile, adult and geriatric), namely delineated adult time points, is crucial in determining molecular mechanisms translatable to human age groups. For example, zebrafish, at $2 \mathrm{ypf}$, exhibit significant diminution in cognitive performance compared to 1ypf using an associative learning test [73]. These researchers found that the aged zebrafish contained increased levels of oxidized lipids and proteins in the dorsal telencephalon. One could also investigate the importance of breeding and care as predictive indicators of cognitive success, or failure, as adult fish, potentially differentiating those cohorts with a greater "cognitive reserve" due to superior conditions during earlier stages of development. These conditions would include the concept of "enriched environ-

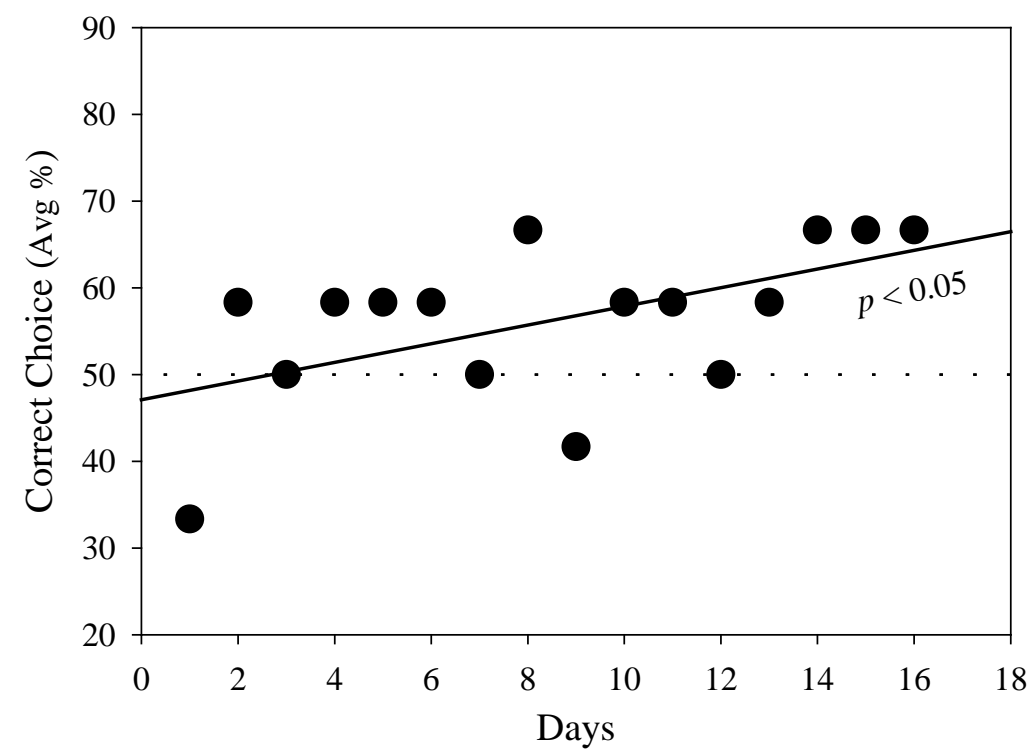

Figure 5. Color discrimination performance in associative learning by adult zebrafish. Six zebrafish (430 dpf/14mpf; or, 41 $\mathrm{H}$-eq years at start) were tested over a 18-day period and their average performance is given over time. The dashed line represents the score expected by chance (i.e. 1 of two possible outcomes, or 50\%). A significant linear regression line ( $p<$ 0.05 ) was calculated using SigmaPlot 12.5 with a formula $y=1.08 x+47.1$. 
ment” as well as nutrition. As with humans, genetics also plays a part in determining "cognitive reserve” in aging. This can be further explored by selective breeding techniques in zebrafish.

\section{Conclusions}

When defining the parameters of POCD, anesthesia represents a distinct area to investigate molecular mechanisms that lead to permanent cognitive loss [75]. While the standard anesthetic combination contains agents that fall into diverse chemical groups, this paper emphasizes the role of inhalational agents (i.e. halogenated ethers), and their analog trifluoroethanol, and how zebrafish may be used to study their action as modulators of cognition and that this modulation may be more toxicological than pharmacological. Zebrafish exhibit rudimentary behaviors: social (i.e. shoaling), emotional (i.e. anxiety) and cognitive (i.e. associative learning). These behaviors, as affected by age and anesthetics, may be charted on a course towards a dementia-like neurophenotype.

Although the rodent model dominates the literature [68] [76]-[78], alternative strategies in animal modeling offer higher throughput for neurophenotype analysis. The zebrafish model is recognized as an important component of translational neuroscience research [35]. Zebrafish have an elaborate behavioral repertoire and are used to test various cognitive endpoints (i.e. attention, learning and memory). These endpoints are amenable to quantitation that can be automated by use of commercially available behavioral analysis programs using specially-designed tanks. Continued research opens the possibility that, in the future, perioperative prophylaxis will prevent POCD.

\section{References}

[1] Savageau, J.A., Stanton, B.A., Jenkins, C.D. and Klein, M.D. (1982) Neuropsychological Dysfunction Following Elective Cardiac Operation. I. Early Assessment. Journal of Thoracic and Cardiovascular Surgery, 84, 585-594.

[2] Selnes, O.A., Royall, R.M., Grega, M.A., Borowicz Jr., L.M., Quaskey, S. and McKhann, G.M. (2001) Cognitive Changes 5 Years after Coronary Artery Bypass Grafting: Is There Evidence of Late Decline? Archives of Neurology, 58, 598-604. http://dx.doi.org/10.1001/archneur.58.4.598

[3] Newman, M.F., Kirchner, J.L., Phillips-Bute, B., Gaver, V., Grocott, H., Jones, R.H., Mark, D.B., Reves, J.G. and Blumenthal, J.A. (2001) Longitudinal Assessment of Neurocognitive Function after Coronary-Artery Bypass Surgery. New England Journal of Medicine, 344, 395-402. http://dx.doi.org/10.1056/NEJM200102083440601

[4] Biedler, A., Juckenhöfel, S., Larsen, R., Radtke, F., Stotz, A., Warmann, J., Braune, E., Dyttkowitz, A., Henning, F., Strickmann, B. and Lauven, P.M. (1999) Postoperative Cognition Disorders in Elderly Patients. The Results of the "International Study of Postoperative Cognitive Dysfunction” (ISPOCD 1). Anaesthesist, 48, 884-895. http://dx.doi.org/10.1007/s001010050802

[5] Huttenlocher, P.R. (1979) Synaptic Density in Human Frontal Cortex-Developmental Changes and Effects of Aging. Brain Research, 163, 195-205. http://dx.doi.org/10.1016/0006-8993(79)90349-4

[6] Palop, J.J. and Mucke, L. (2010) Amyloid-Beta-Induced Neuronal Dysfunction in Alzheimer's Disease: From Synapses toward Neural Networks. Nature Neuroscience, 13, 812-818. http://dx.doi.org/10.1038/nn.2583

[7] Vanderweyde, T., Bednar, M.M., Forman, S.A. and Wolozin, B. (2010) Iatrogenic Risk Factors for Alzheimer's Disease: Surgery and Anesthesia. Journal of Alzheimer's Disease, 22, 91-104.

[8] Xie, Z. and Tanzi, R.E. (2006) Alzheimer's Disease and Post-Operative Cognitive Dysfunction. Experimental Gerontology, 41, 346-359. http://dx.doi.org/10.1016/j.exger.2006.01.014

[9] Kokmen, E., Whisnant, J.P., O’Fallon, W.M., Chu, C.P. and Beard, C.M. (1996) Dementia after Ischemic Stroke: A Population-Based Study in Rochester, Minnesota (1960-1984). Neurology, 46, 154-159. http://dx.doi.org/10.1212/WNL.46.1.154

[10] Moroney, J.T., Bagiella, E., Desmond, D.W., Paik, M.C., Stern, Y. and Tatemichi, T.K. (1996) Risk Factors for Incident Dementia after Stroke. Role of Hypoxic and Ischemic Disorders. Stroke, 27, 1283-1289. http://dx.doi.org/10.1161/01.STR.27.8.1283

[11] Xie, Z., Moir, R.D., Romano, D.M., Tesco, G., Kovacs, D.M. and Tanzi, R.E. (2004) Hypocapnia Induces Caspase-3 Activation and Increases Abeta Production. Neurodegenerative Diseases, 1, 29-37. http://dx.doi.org/10.1159/000076667

[12] Ramlawi, B., Rudolph, J.L., Mieno, S., Feng, J., Boodhwani, M., Khabbaz, K., Levkoff, S.E., Marcantonio, E.R., Bianchi, C. and Sellke, F.W. (2006) C-Reactive Protein and Inflammatory Response Associated to Neurocognitive Decline Following Cardiac Surgery. Surgery, 140, 221-226. http://dx.doi.org/10.1016/j.surg.2006.03.007

[13] Steinmetz, J., Christensen, K.B., Lund, T., Lohse, N. and Rasmussen, L.S., ISPOCD Group (2009) Long-Term Con- 
sequences of Postoperative Cognitive Dysfunction. Anesthesiology, 110, 548-555. http://dx.doi.org/10.1097/ALN.0b013e318195b569

[14] Seitz, D.P., Reimer, C.L. and Siddiqui, N. (2013) A Review of Epidemiological Evidence for General Anesthesia as a Risk Factor for Alzheimer's Disease. Progress in Neuro-Psychopharmacology \&Biological Psychiatry, 47, $122-127$. http://dx.doi.org/10.1016/j.pnpbp.2012.06.022

[15] Papon, M.A., Whittington, R.A., El-Khoury, N.B. and Planel, E. (2011) Alzheimer’s Disease and Anesthesia. Frontiers in Neuroscience, 4, 272. http://dx.doi.org/10.3389/fnins.2010.00272

[16] Tang, J., Eckenhoff, M.F. and Eckenhoff, R.G. (2010) Anesthesia and the Old Brain. Anesthesia \& Analgesia, 110, 421-426. http://dx.doi.org/10.1213/ane.0b013e3181b80939

[17] Xie, Z. and Xu, Z. (2013) General Anesthetics and $\beta$-Amyloid Protein. Progress in Neuro-Psychopharmacology and Biological Psychiatry, 47, 140-146. http://dx.doi.org/10.1016/i.pnpbp.2012.08.002

[18] Bedford, P.D. (1955) Adverse Cerebral Effects of Anesthesia on Old People. The Lancet, 266, 259-264. http://dx.doi.org/10.1016/S0140-6736(55)92689-1

[19] Murkin, J.M., Newman, S.P., Stump, D.A. and Blumenthal, J.A. (1995) Statement of Consensus on Assessment of Neurobehavioral Outcomes after Cardiac Surgery. The Annals of Thoracic Surgery, 59, 1289-1295. http://dx.doi.org/10.1016/0003-4975(95)00106-U

[20] Stern, Y., Gurland, B., Tatemichi, T.K., Tang, M.X., Wilder, D. and Mayeux, R. (1994) Influence of Education and Occupation on the Incidence of Alzheimer's Disease. Journal of the American Medical Association, 271, $1004-1010$. http://dx.doi.org/10.1001/jama.1994.03510370056032

[21] Slooter, A.J., van Duijn, C.M., Bots, M.L., Ott, A., Breteler, M.B., De Voecht, J., Wehnert, A., de Knijff, P., Havekes, L.M., Grobbee, D.E., Van Broeckhoven, C. and Hofman, A. (1998) Apolipoprotein E Genotype, Atherosclerosis, and Cognitive Decline: The Rotterdam Study. Journal of Neural Transmission, 53, 17-29. http://dx.doi.org/10.1007/978-3-7091-6467-9 3

[22] Wilson, R.S., Beckett, L.A., Bennett, D.A., Albert, M.S. and Evans, D.A. (1999) Change in Cognitive Function in Older Persons from a Community Population: Relation to Age and Alzheimer Disease. Archives of Neurology, 56, 1274-1279. http://dx.doi.org/10.1001/archneur.56.10.1274

[23] Small, S.A., Stern, Y., Tang, M. and Mayeux, R. (1999) Selective Decline in Memory Function among Healthy Elderly. Neurology, 52, 1392-1396. http://dx.doi.org/10.1212/WNL.52.7.1392

[24] Newman, S.K., Warrington, E.K., Kennedy, A.M. and Rossor, M.N. (1994) The Earliest Cognitive Change in a Person with Familial Alzheimer's Disease: Presymptomatic Neuropsychological Features in a Pedigree with Familial Alzheimer's Disease Confirmed at Necropsy. Journal of Neurology, Neurosurgery, and Psychiatry, 57, 967-972. http://dx.doi.org/10.1136/jnnp.57.8.967

[25] Jendroska, K., Hoffmann, O.M. and Patt, S. (1997) Amyloid $\beta$ Peptide and Precursor Protein (APP) in Mild and Severe Brain Ischemia. Annals of the New York Academy of Sciences, 826, 401-405. http://dx.doi.org/10.1111/j.1749-6632.1997.tb48492.x

[26] Kalaria, R.N. (2000) The Role of Cerebral Ischemia in Alzheimer’s Disease. Neurobiology of Aging, 21, 321-330. http://dx.doi.org/10.1016/S0197-4580(00)00125-1

[27] Webster, N.J., Green, K.N., Peers, C. and Vaughan, P.F. (2002) Altered Processing of Amyloid Precursor Protein in the Human Neuroblastoma SH-SY5Y by Chronic Hypoxia. Journal of Neurochemistry, 83, 1262-1271. http://dx.doi.org/10.1046/j.1471-4159.2002.01236.X

[28] Hu, Z., Ou, Y., Duan, K. and Jiang, X. (2010) Inflammation: A Bridge between Postoperative Cognitive Dysfunction and Alzheimer's Disease. Medical Hypotheses, 74, 722-724. http://dx.doi.org/10.1016/j.mehy.2009.10.040

[29] Wilson, C.J., Finch, C.E. and Cohen, H.J. (2002) Cytokines and Cognition-The Case for a Head-to-Toe Inflammatory Paradigm. Journal of the American Geriatrics Society, 50, 2041-2056. http://dx.doi.org/10.1046/j.1532-5415.2002.50619.x

[30] Minagar, A., Shapshak, P., Fujimura, R., Ownby, R., Heyes, M. and Eisdorfer, C. (2002) The Role of Macrophage/ Microglia and Astrocytes in the Pathogenesis of Three Neurologic Disorders: HIV Associated Dementia, Alzheimer Disease, and Multiple Sclerosis. Journal of the Neurological Sciences, 202, 13-23. http://dx.doi.org/10.1016/S0022-510X(02)00207-1

[31] Dong, Y., Zhang, G., Zhang, B., Moir, R.D., Xia, W., Marcantonio, E.R., Culley, D.J., Crosby, G., Tanzi, R.E. and Xie, Z. (2009) The Common Inhalational Anesthetic Sevoflurane Induces Apoptosis and Increases $\beta$-Amyloid Protein Levels. Archives of Neurology, 66, 620-631. http://dx.doi.org/10.1001/archneurol.2009.48

[32] Planel, E., Richter, K.E., Nolan, C.E., Finley, J.E., Liu, L., Wen, Y., Krishnamurthy, P., Herman, M., Wang, L., Schachter, J.B., Nelson, R.B., Lau, L.F. and Duff, K.E. (2007) Anesthesia Leads to Tau Hyperphosphorylation through Inhibition of Phosphatase Activity by Hypothermia. Journal of Neuroscience, 27, 3090-3097. 
http://dx.doi.org/10.1523/JNEUROSCI.4854-06.2007

[33] Kins, S., Crameri, A., Evans, D.R., Hemmings, B.A., Nitsch, R.M. and Gotz, J. (2001) Reduced Protein Phosphatase 2A Activity Induces Hyperphosphorylation and Altered Compartmentalization of Tau in Transgenic Mice. Journal of Biological Chemistry, 276, 38193-38200.

[34] Culley, D.J., Baxter, M.G., Yukhananov, R. and Crosby, G. (2004) Long-Term Impairment of Acquisition of a Spatial Memory Task Following Isoflurane-Nitrous Oxide Anesthesia in Rats. Anesthesiology, 100, 309-314. http://dx.doi.org/10.1097/00000542-200402000-00020

[35] Li, Z., Cao, Y., Li, L., Liang, Y., Tian, X., Mo, N., Liu, Y., Li, M., Chui, D. and Guo, X. (2014) Prophylactic Angiotensin Type 1 Receptor Antagonism Confers Neuroprotection in an Aged Rat Model of Postoperative Cognitive Dysfunction. Biochemical and Biophysical Research Communications, 449, 74-80. http://dx.doi.org/10.1016/j.bbrc.2014.04.153

[36] Xu, Z., Dong, Y., Wang, H., Culley, D.J., Marcantonio, E.R., Crosby, G., Tanzi, R.E., Zhang, Y. and Xie, Z. (2014) Age-Dependent Postoperative Cognitive Impairment and Alzheimer-Related Neuropathology in Mice. Scientific Reports, 4, 3766. http://dx.doi.org/10.1038/srep03766

[37] Hu, N., Guo, D., Wang, H., Xie, K., Wang, C., Li, Y., Wang, C., Wang, C., Yu, Y. and Wang, G. (2014) Involvement of the Blood-Brain Barrier Opening in Cognitive Decline in Aged Rats Following Orthopedic Surgery and High Concentration of Sevoflurane Inhalation. Brain Research, 1551, 13-24. http://dx.doi.org/10.1016/j.brainres.2014.01.015

[38] Luo, X., Yang, L., Chen, X. and Li, S. (2014) Tau Hyperphosphorylation: A Downstream Effector of Isoflurane-Induced Neuroinflammation in aged rodents. Medical Hypotheses, 82, 94-96. http://dx.doi.org/10.1016/j.mehy.2013.11.015

[39] Chi, H., Kawano, T., Tamura, T., Iwata, H., Takahashi, Y., Eguchi, S., Yamazaki, F., Kumagai, N. and Yokoyama, M. (2013) Postoperative Pain Impairs Subsequent Performance on a Spatial Memory Task via Effects on N-Methyl-DAspartate Receptor in Aged Rats. Life Sciences, 93, 986-993. http://dx.doi.org/10.1016/j.lfs.2013.10.028

[40] Hovens, I.B., Schoemaker, R.G., van der Zee, E.A., Heineman, E., Nyakas, C. and van Leeuwen, B.L. (2013) Surgery-Induced Behavioral Changes in Aged Rats. Experimental Gerontology, 48, 1204-1211. http://dx.doi.org/10.1016/j.exger.2013.07.011

[41] Kalb, A., von Haefen, C., Sifringer, M., Tegethoff, A., Paeschke, N., Kostova, M., Feldheiser, A. and Spies, C.D. (2013) Acetylcholinesterase Inhibitors Reduce Neuroinflammation and -Degeneration in the Cortex and Hippocampus of a Surgery Stress Rat Model. PLoS ONE, 8, e62679. http://dx.doi.org/10.1371/journal.pone.0062679

[42] Kong, F., Chen, S., Cheng, Y., Ma, L., Lu, H., Zhang, H. and Hu, W. (2013) Minocycline Attenuates Cognitive Impairment Induced by Isoflurane Anesthesia in Aged Rats. PLoS ONE, 8, e61385. http://dx.doi.org/10.1371/journal.pone.0061385

[43] Wu, X., Lu, Y., Dong, Y., Zhang, G., Zhang, Y., et al. (2012) The Inhalation Anesthetic Isoflurane Increases Levels of Proinflammatory TNF- $\alpha$, IL-6, and IL-1 $\beta$. Neurobiology of Aging, 33, 1364-1378. http://dx.doi.org/10.1016/j.neurobiolaging.2010.11.002

[44] Wang, H., Xu, Z., Feng, C., Wang, Y., Jia, X., Wu, A. and Yue, Y. (2012) Changes of Learning and Memory in Aged Rats after Isoflurane Inhalational Anaesthesia Correlated with Hippocampal Acetylcholine Level. Annales Françaises d'Anesthésie et de Réanimation, 31, e61-e66. http://dx.doi.org/10.1016/j.annfar.2011.02.005

[45] Best, J.D. and Alderton, W.K. (2008) Zebrafish: An in Vivo Model for the Study of Neurological Diseases. Neuropsychiatric Disease and Treatment, 4, 567-576. http://dx.doi.org/10.2147/NDT.S2056

[46] Newman, M., Verdile, G., Martins, R.N. and Lardelli, M. (2011) Zebrafish as a Tool in Alzheimer's Disease Research. Biochimica et Biophysica Acta (BBA)-Molecular Basis of Disease, 1812, 346-352. http://dx.doi.org/10.1016/j.bbadis.2010.09.012

[47] Foley, J.A., Kaschel, R., Logie, R.H. and Della Sala, S. (2011) Dual-Task Performance in Alzheimer’s Disease, Mild Cognitive Impairment, and Normal Ageing. Archives of Clinical Neuropsychology, 26, 340-348. http://dx.doi.org/10.1093/arclin/acr032

[48] Kishi, S. (2013) Using Zebrafish Models to Explore Genetic and Epigenetic Impacts on Evolutionary Developmental Origins of Aging. Translational Research, 163, 123-135. http://dx.doi.org/10.1016/j.trsl.2013.10.004

[49] Sasaki, T. and Kishi, S. (2013) Molecular and Chemical Genetic Approaches to Developmental Origins of Aging and Disease in Zebrafish. Biochimica et Biophysica Acta (BBA)-Molecular Basis of Disease, 1832, 1362-1370. http://dx.doi.org/10.1016/j.bbadis.2013.04.030

[50] Zhdanova, I.V., Yu, L., Lopez-Patino, M., Shang, E., Kishi, S. and Guelin, E. (2008) Aging of the Circadian System in Zebrafish and the Effects of Melatonin on Sleep and Cognitive Performance. Brain Research Bulletin, 75, 433-441. http://dx.doi.org/10.1016/j.brainresbull.2007.10.053

[51] Kishi, S., Slack, B.E., Uchiyama, J. and Zhdanova, I.V. (2009) Zebrafish as a Genetic Model in Biological and Beha- 
vioral Gerontology: Where Development Meets Aging in Vertebrates_A Mini-Review. Gerontology, 55, 430-441. http://dx.doi.org/10.1159/000228892

[52] Kishi, S., Bayliss, P.E., Uchiyama, J., Koshimizu, E., Qi, J., Nanjappa, P., Imamura, S., Islam, A., Neuberg, D., Amsterdam, A. and Roberts, T.M. (2008) The Identification of Zebrafish Mutants Showing Alterations in Senescence-Associated Biomarkers. PLoS Genetics, 4, e1000152. http://dx.doi.org/10.1371/journal.pgen.1000152

[53] Kishi, S., Uchiyama, J., Baughman, A.M., Goto, T., Lin, M.C. and Tsai, S.B. (2003) The Zebrafish as a Vertebrate Model of Functional Aging and Very Gradual Senescence. Experimental Gerontology, 38, 777-786. http://dx.doi.org/10.1016/s0531-5565(03)00108-6

[54] Yu, L., Tucci, V., Kishi, S. and Zhdanova, I.V. (2006) Cognitive Aging in Zebrafish. PLoS ONE, 1, e14. http://dx.doi.org/10.1371/journal.pone.0000014

[55] Parichy, D.M., Elizondo, M.R., Mills, M.G., Gordon, T.N. and Engeszer, R.E. (2009) Normal Table of Postembryonic Zebrafish Development: Staging by Externally Visible Anatomy of the Living Fish. Developmental Dynamics, 238, 2975-3015. http://dx.doi.org/10.1002/dvdy.22113

[56] Hopwood, N. (2007) A History of Normal Plates, Tables and Stages in Vertebrate Embryology. The International Journal of Developmental Biology, 51, 1-26. http://dx.doi.org/10.1387/ijdb.062189nh

[57] Gerhard, G.S., Kauffman, E.J., Wang, X., Stewart, R., Moore, J.L., Kasales, C.J., Demidenko, E. and Cheng, K.C. (2002) Life Spans and Senescent Phenotypes in Two Strains of Zebrafish (Danio rerio). Experimental Gerontology, 37, 1055-1068. http://dx.doi.org/10.1016/s0531-5565(02)00088-8

[58] Weon, B.M. and Je, J.H. (2009) Theoretical Estimation of Maximum Human Lifespan. Biogerontology, 10, 65-71. http://dx.doi.org/10.1007/s10522-008-9156-4

[59] Steinberg, L.A. (2008) Social Neuroscience Perspective on Adolescent Risk-Taking. Developmental Review, 28, 78106. http://dx.doi.org/10.1016/j.dr.2007.08.002

[60] Casey, B.J., Davidson, M.C., Hara, Y., Thomas, K.M., Martinez, A., Galvan, A., Halperin, J.M., Rodríguez-Aranda, C.E. and Tottenham, N. (2004) Early Development of Subcortical Regions Involved in Non-Cued Attention Switching. Developmental Science, 7, 534-542. http://dx.doi.org/10.1111/j.1467-7687.2004.00377.x

[61] Stewart, A.M. and Kalueff, A.V. (2012) The Developing Utility of Zebrafish Models for Cognitive Enhancers Research. Current Neuropharmacology, 10, 263-271. http://dx.doi.org/10.2174/157015912803217323

[62] Levin, E.D., McClernon, F.J. and Rezvani, A.H. (2006) Nicotinic Effects on Cognitive Function: Behavioral Characterization, Pharmacological Specification, and Anatomic Localization. Psychopharmacology, 184, 523-539. http://dx.doi.org/10.1007/s00213-005-0164-7

[63] Bencan, Z. and Levin, E.D. (2008) The Role of $\alpha 7$ and $\alpha 4 \beta 2$ Nicotinic Receptors in the Nicotine-Induced Anxiolytic Effect in Zebrafish. Physiology \& Behavior, 95, 408-412. http://dx.doi.org/10.1016/j.physbeh.2008.07.009

[64] Angelucci, M.E., Vital, M.A., Cesário, C., Zadusky, C.R., Rosalen, P.L. and Da Cunha, C. (1999) The Effect of Caffeine in Animal Models of Learning and Memory. European Journal of Pharmacology, 373, 135-140. http://dx.doi.org/10.1016/S0014-2999(99)00225-3

[65] Riehl, R., Kyzar, E., Allain, A., Green, J., Hook, M., Monnig, L., Rhymes, K., Roth, A., Pham, M., Razavi, R., Dileo, J., Gaikwad, S., Hart, P. and Kalueff, A.V. (2011) Behavioral and Physiological Effects of Acute Ketamine Exposure in Adult Zebrafish. Neurotoxicology and Teratology, 33, 658-667. http://dx.doi.org/10.1016/j.ntt.2011.05.011

[66] Kim, Y.H., Lee, Y., Kim, D., Jung, M.W. and Lee, C.J. (2010) Scopolamine-Induced Learning Impairment Reversed by Physostigmine in Zebrafish. Neuroscience Research, 67, 156-161. http://dx.doi.org/10.1016/j.neures.2010.03.003

[67] Sison, M. and Gerlai, R. (2011) Associative Learning Performance Is Impaired in Zebrafish (Danio rerio) by the NMDA-R Antagonist MK-801. Neurobiology of Learning and Memory, 96, 230-237. http://dx.doi.org/10.1016/j.nlm.2011.04.016

[68] Carvan III, M.J., Loucks, E., Weber, D.N. and Williams, F.E. (2004) Ethanol Effects on the Developing Zebrafish: Neurobehavior and Skeletal Morphogenesis. Neurotoxicology and Teratology, 26, 757-768. http://dx.doi.org/10.1016/j.ntt.2004.06.016

[69] Lee, Y., Lee, B., Jeong, S., Park, J.W., Han, I.O. and Lee, C.J. (2016) Increased Cell Proliferation and Neural Activity by Physostigmine in the Telencephalon of Adult Zebrafish. Neuroscience Letters, 629, 189-195. http://dx.doi.org/10.1016/j.neulet.2016.07.001

[70] Dirnagl, U., Becker, K. and Meisel, A. (2009) Preconditioning and Tolerance against Cerebral Ischaemia: From Experimental Strategies to Clinical Use. The Lancet Neurology, 8, 398-412. http://dx.doi.org/10.1016/S1474-4422(09)70054-7

[71] Mustard, J., Strope, M., Havey, C., Wang, L. and Seidler, N. (2016) Neurophenotyping of Zebrafish Larvae That Are Preconditioned with Anesthetic Agent. Journal of Behavioral and Brain Science, 6, 99-106. 
http://dx.doi.org/10.4236/jbbs.2016.62011

[72] Owen, B.E. and Taberner, P.V. (1980) Studies on the Hypnotic Effects of Chloral Hydrate and Ethanol and Their Metabolism in Vivo and in Vitro. Biochemical Pharmacology, 29, 3011-3016. http://dx.doi.org/10.1016/0006-2952(80)90051-9

[73] Ruhl, T., Jonas, A., Seidel, N., Prinz, N., Albayram, O., Bilkei-Gorzo, A. and von der Emde, G. (2016) Oxidation and Cognitive Impairment in the Aging Zebrafish. Gerontology, 62, 47-57. http://dx.doi.org/10.1159/000433534

[74] Bortolotto, J.W., Melo, G.M., CognatoGde, P., Vianna, M.R. and Bonan, C.D. (2015) Modulation of Adenosine Signaling Prevents Scopolamine-Induced Cognitive Impairment in Zebrafish. Neurobiology of Learning and Memory, 118, 113-119. http://dx.doi.org/10.1016/j.nlm.2014.11.016

[75] Eckenhoff, R.G. and Laudansky, K.F. (2013) Anesthesia, Surgery, Illness and Alzheimer's Disease. Progress in Neuro-Psychopharmacology and Biological Psychiatry, 47, 162-166. http://dx.doi.org/10.1016/j.pnpbp.2012.06.011

[76] Li, C., Liu, S., Xing, Y. and Tao, F. (2014) The Role of Hippocampal Tau Protein Phosphorylation in Isoflurane-Induced Cognitive Dysfunction in Transgenic APP695 Mice. Anesthesia \& Analgesia, 119, 413-419. http://dx.doi.org/10.1213/ANE.0000000000000315

[77] Wang, Y., He, H., Li, D., Zhu, W., Duan, K., Le, Y., Liao, Y. and Ou, Y. (2013) The Role of the TLR4 Signaling Pathway in Cognitive Deficits Following Surgery in Aged Rats. Molecular Medicine Reports, 7, 1137-1142.

[78] Bruce-Keller, A.J., Gupta, S., Knight, A.G., Beckett, T.L., McMullen, J.M., Davis, P.R., Murphy, M.P., Van Eldik, L.J., St Clair, D. and Keller, J.N. (2011) Cognitive Impairment in Humanized APP $\times$ PS1 Mice Is Linked to A $\beta_{1-42}$ and NOX Activation. Neurobiology of Disease, 44, 317-326. http://dx.doi.org/10.1016/j.nbd.2011.07.012

[79] Johnson, T., Monk, T., Rasmussen, L.S., Abildstrom, H., Houx, P., Korttila, K., Kuipers, H.M., Hanning, C.D., Siersma, V.D., Kristensen, D., Canet, J., Ibañaz, M.T. and Moller, J.T., ISPOCD2 Investigators (2002) Postoperative Cognitive Dysfunction in Middle-Aged Patients. Anesthesiology, 96, 1351-1357. http://dx.doi.org/10.1097/00000542-200206000-00014

[80] Canet, J., Raeder, J., Rasmussen, L.S., Enlund, M., Kuipers, H.M., Hanning, C.D., Jolles, J., Korttila, K., Siersma, V.D., Dodds, C., Abildstrom, H., Sneyd, J.R., Vila, P., Johnson, T., Muñoz Corsini, L., Silverstein, J.H., Nielsen, I.K. and Moller, J.T., ISPOCD2 Investigators (2003) Cognitive Dysfunction after Minor Surgery in the Elderly. Acta Anaesthesiologica Scandinavica, 47, 1204-1210. http://dx.doi.org/10.1046/j.1399-6576.2003.00238.x

[81] Howe, K., Clark, M.D., Torroja, C.F., Torrance, J., Berthelot, C., Muffato, M., et al. (2013) The Zebrafish Reference Genome Sequence and Its Relationship to the Human Genome. Nature, 496, 498-503. http://dx.doi.org/10.1038/nature12111

\section{Submit or recommend next manuscript to SCIRP and we will provide best service for you:}

Accepting pre-submission inquiries through Email, Facebook, LinkedIn, Twitter, etc. A wide selection of journals (inclusive of 9 subjects, more than 200 journals)

Providing 24-hour high-quality service

User-friendly online submission system

Fair and swift peer-review system

Efficient typesetting and proofreading procedure

Display of the result of downloads and visits, as well as the number of cited articles

Maximum dissemination of your research work

Submit your manuscript at: http://papersubmission.scirp.org/ 